\title{
Who is the gate keeper for treatment in a fertility clinic in Germany? -baseline results of a prospective cohort study (PinK study)-
}

Eva Münster ${ }^{1,2,3^{*}}$, Stephan Letzel ${ }^{2}$, Jasmin Passet-Wittig ${ }^{3}$, Norbert F. Schneider ${ }^{3}$, Bettina Schuhrke ${ }^{4}$, Rudolf Seufert ${ }^{5}$ and Ulrike Zier $^{2}$

\begin{abstract}
Background: It is estimated that $5-15 \%$ of all couples in industrialised nations are infertile. A perceived unfulfilled desire for a child or self-identification as infertile can lead to psychological strain and social isolation. About 53.000 women underwent assisted reproduction treatments in Germany in 2014. Little is known about the first medical consultation and patient needs prior to the first visit in a fertility clinic in Germany. The baseline survey of the prospective cohort study on couples undergoing fertility treatment in Germany (PinK Study) provides first results on this topic for Germany.

Methods: The baseline survey was conducted between 2012 and 2013. Self-administered questionnaires were handed out to patients of six fertility clinics at the beginning of treatment by clinic staff. At a participation rate of $31.0 \%$, we were able to analyse data on 323 women and 242 men.

Results: $92.6 \%$ of the women had their initial medical consultation on their unfulfilled desire for a child with a gynaecologist. After the urologist (44.2\%), the general practitioner (12.0\%) was the second most approached initial contact person for men. $36.4 \%$ of all men had no medical consultation on the unfulfilled desire for a child before visiting a fertility clinic. $46.9 \%$ of the respondents expressed the wish that the conversation about infertility should be initiated by a physician. Prior to their first visit to a fertility clinic, $11.2 \%$ of the men and $24.8 \%$ of the women were informed by a physician that infertility treatment can cause emotional strain.

Conclusion: While almost all women consult a gynaecologist prior to the first visit in a fertility centre, one out of three men do not consult any physician at that stage. For the remaining group of men, urologists and general practitioners are the most important contact persons. Gender-specific health care needs are evident. In order to close the health care gap for men in Germany, more opportunities for discreet access to consultation should be offered. Due to its low threshold and family-oriented approach, general practice could make an important contribution to this effect.
\end{abstract}

Keywords: Infertility, Fertility, First consultation, Men, Patient information, Epidemiology, Public health, Germany

\footnotetext{
* Correspondence: eva.muenster@ukb.uni-bonn.de

${ }^{1}$ Institute of General Practice and Family Medicine, University of Bonn, Bonn,

Germany

${ }^{2}$ Institute of Occupational, Social and Environmental Medicine, University

Medical Center of the University of Mainz, Mainz, Germany

Full list of author information is available at the end of the article
} 


\section{Background}

An unfulfilled desire for a child and the self-identification as infertile can create an emotionally extreme situation for women and men as well as the whole couple [1-4]. Even lower levels of strain can lead to increased personal and relationship stress as well as social withdrawal $[1,5,6]$. Furthermore it has been reported that during fertility treatment more than $50 \%$ of the patients experience some degree of emotional distress and about $23 \%$ discontinue prematurely because of the perceived burden of treatment [7].

Although some have argued against the possibility of an objective definition of infertility that would ignore the self-perceptions of patients [8], according to the World Health Organization, infertility is to be understood as the failure of a couple to conceive after 12 months or more of regular unprotected sexual intercourse [9].

In accordance with this latter definition, it is estimated that between $5 \%$ and $15 \%$ of all couples in industrialised nations face current infertility [10]. There is a lack of reliable current data on the prevalence of infertility in Germany. A telephone survey in 1998 found a point prevalence of the phenomenon of $3 \%$ and a lifetime prevalence of $15 \%$ in women aged between 20 and 44 years [11]. Using data from the IMS Disease Analyzer database containing information on patients of 2500 practices of general practitioners and specialists, Ziller et al. [12] estimated that $8.9 \%$ of all women aged $18-45$ consulted a physician to get information, testing or treatment concerning infertility between 2006 and 2010. However, assisted reproduction technology (ART) treatments are on the rise [13]. In Germany, 57.998 women have undergone in vitro fertilisation (IVF) or intracytoplasmic sperm injection (ICSI) in 2015 [14]. In Germany, 530.240 women have undergone these kinds of treatments between 1997 and 2014 [15] and 233.749 babies were born as a result of them within the same time frame [14]. It is estimated that worldwide, about 5 million babies have been born due to ART treatments since 1978 [16]. At 6.1\%, Germany's neighbouring country Denmark had the highest share of births associated with ART treatment in Europe in 2012 [13].

Access to ART treatments as well as the requirement of comprehensive patient information, treatment indications and admission requirements for physicians are regulated by professional guidelines in Germany [17]. Physicians accredited by statutory health insurance may administer ART treatments to patients only after referral by an independent family doctor or specialist. This referral to a fertility clinic requires that both partners have to have been informed on the medical, psychological and social aspects of ART and insemination by the referrer. Furthermore, the indicating diagnosis of infertility has to be a confirmed one [18].
Health effects of the unfulfilled desire for a child as well as of an ART treatment are often underestimated [19]. ART treatments pose health risks especially to women. One of the dreaded side effects is the ovarian hyperstimulation syndrome (OHSS) which can lead to severe health impairments. Another health risk is posed by the increased rate of multiple and premature births. The treatment itself and the involved periods of waiting often cause strong emotional strain to patients [20-23]. The gate keeper to the fertility clinic thus takes over a significant role: $\mathrm{He} / \mathrm{she}$ has to be selective in offering ART treatments and is required to inform about the possible risks of such treatments before he/she gives the referral.

Regarding Germany, success rates of ART treatments are reported to be lower than $20 \%$ per treatment cycle $[13,15,22]$. However, the prospect of success of these treatments is overestimated by $2 / 3 \mathrm{rds}$ of the German population [24].

In addition to ensuring the comprehensive education of the general population on infertility and its risk factors, a further aim of public health should be the reduction of psychosocial stress situations by supporting infertile couples by means of consultations and counselling early on. Therefore, the first medical consultations on infertility as well as the decision on whether a referral to a fertility clinic is made are highly significant.

Despite the relevance of unfulfilled desires for a child for public health, there is a lack of comprehensive medical survey data on the subject in Germany. From our point of view, the following questions are of particular interest: Which type of doctor conducts the first medical consultation with women and men with an unfulfilled desire for a child? Does the patient or the doctor initiate the first consultation and which is preferred by the patient? Are patients being informed about the potential emotional strain during ART treatments before their first visit to a fertility clinic?

Now for the first time, these aspects can be examined in the interdisciplinary survey of couples in infertility treatment (PinK study).

\section{Methods}

A methodological report of the PinK study has already been published [25]. The PinK study is a prospective survey on patients at all seven sites in six cities of the five fertility clinics in Rhineland-Palatinate and the fertility clinic in the capital city of Hesse (Wiesbaden). Using a standardised gender-specific questionnaire in German and Turkish language to be completed by each partner separately at home and returned by return envelope, the study's anonymous baseline survey was conducted between July 2012 and May 2013. The study documents 
were handed to couples by staff members of fertility clinics if the following eligibility criteria were met:

1. At least one of the partners had their primary residence in Germany.

2. At least one of the partners had to have sufficient knowledge of the German or Turkish language to fill out the questionnaire.

3. The couple was just beginning their treatment at the fertility clinic. The study documents were handed over during the informed consent discussion for the first treatment (not necessarily ART) at the clinic.

Patients or couples, who had already been in treatment at the same fertility clinic and were for example changing the type of treatment they were receiving, were excluded from the survey.

At a participation rate of $31.0 \%$, data on 565 subjects (323 women and 242 men) could be analysed. In 234 patient couples, both partners participated in the survey.

\section{Variables}

To describe the overall study population as well as gender subgroups, the socio-demographic variables age, marital status, parity, health insurance type and education level were used. Educational attainment was measured by "International Standard Classification of Education (ISCED)" level and categorized into "low", "medium" and "high" [25].

The main findings are based on the following questions:

1. Before your very first visit to a fertility clinic, which doctor did you first speak to about not getting pregnant?

2. Did the doctor initiate the conversation about the topic "not getting pregnant"?

3. Do you think that doctors should initiate a conversation about that topic on their own accord? Have you previously been informed by a doctor that treatment at a fertility clinic can possibly be emotionally stressful for you? If so, when?

Missing values ("not specified") were assigned to the reference category ("ref.") if they accounted for less than $2 \%$ of cases. Otherwise they were assigned their own category.

\section{Statistical methods}

Group differences between genders were evaluated by means of Chi-Squared tests and, in case of the nonlinear continuous age variable, the Mann-Whitney U test using statistical software SPSS 22. Statistical significance was defined as $\alpha<0.05$.

\section{Results}

The overall study population of 565 subjects is $34.3 \pm$ 5.3 years old on average (median: 34 ) with women being significantly younger at $32.8 \pm 4.4$ years of age (min.: 22 , max.: 44, median: 32 ) than men at $36.2 \pm 5.9$ years of age (min.: 23, max.: 62, median: 35). $85.0 \%$ of the participants are married. $85.0 \%$ is also the number of those who have no children. $44.2 \%$ are assigned to the category "medium level of education" (see Table 1). At 87.9\%, women do significantly $(p=0.01)$ more often have statutory health insurance instead of private insurance than men with $80.2 \%$.

Information on outcomes concerning the first medical consultation is shown in Table 2. More than one third of the men stated that they had not consulted a doctor prior to their first visit at a fertility clinic. The same was only the case for $2.5 \%$ of the women. $92.6 \%$ of the female subjects had had their first consultation about not getting pregnant with their gynaecologist, $44.2 \%$ of the male subjects had spoken to an urologist. $6.9 \%$ of all subjects had chosen their general practitioner (GP) as their first contact person. The GP was chosen significantly more often by men (12.0\%) than by women (3.1\%). $5.8 \%$ of men named their partner's gynaecologist as their first contact person. The category "other" includes endocrinologists, haematologists and andrologists.

Approximately one out of four women and one out of ten men reported that the physician first contacted by them had initiated the conversation about the pair's potential infertility on his own account. $46.9 \%$ of all subjects, more than half of all women and every third men, advocated that doctors should address the topic themselves. $81.0 \%$ of those who were in fact approached by the doctor stated that doctors should choose this course of action.

Less than one in 5 participants (every 9th man and every 4th woman) was informed by a doctor prior to their visit to a fertility clinic that an ART treatment could be emotionally straining (see Fig. 1).

\section{Discussion}

The written PinK survey of 565 patients in fertility clinics in the south-west of Germany allows insight into the health service pathways of patients at the beginning of infertility treatment in Germany for the first time. It shows that medical needs and utilisation of services differ in men and women with an unfulfilled desire for a child. While nine out of ten women had spoken to their gynaecologists about the unfulfilled desire for a child, every third man had not spoken about the problem to any physician at all prior to their first visit to a fertility clinic. After the urologist, the GP was the most important contact person regarding the unfulfilled desire for a child for men (12.0\%), followed by their partner's gynaecologist. 
Table 1 Socio-economic characteristics of the study population of the PinK study, stratified by gender

\begin{tabular}{|c|c|c|c|c|c|c|c|}
\hline & Total & & Men & & Women & & $p$-value \\
\hline & $n=565$ & $\%$ & $n=242$ & $\%$ & $n=323$ & $\%$ & \\
\hline Age groups (in years) & & & & & & & $<0.001$ \\
\hline$<35$ (ref.) & 317 & 56.1 & 108 & 44.6 & 209 & 64.7 & \\
\hline$\geq 35$ & 248 & 43.9 & 134 & 55.4 & 114 & 35.3 & \\
\hline Marital status & & & & & & & 0.078 \\
\hline Married (ref.) & 480 & 85.0 & 213 & 88.0 & 267 & 82.7 & \\
\hline Not married & 85 & 15.0 & 29 & 12.0 & 56 & 17.3 & \\
\hline Parity & & & & & & & 0.888 \\
\hline Childless (ref.) & 480 & 85.0 & 205 & 84.7 & 275 & 85.1 & \\
\hline One child or more & 85 & 15.0 & 37 & 15.3 & 48 & 14.9 & \\
\hline Health Insurance Status & & & & & & & 0.011 \\
\hline Statutory (ref.) & 478 & 84.6 & 194 & 80.2 & 284 & 87.9 & \\
\hline Private & 87 & 15.4 & 48 & 19.8 & 39 & 12.1 & \\
\hline Education level (ISCED) & & & & & & & 0.059 \\
\hline Low & 20 & 3.5 & 11 & 4.5 & 9 & 2.8 & \\
\hline Medium (ref.) & 250 & 44.2 & 94 & 38.8 & 156 & 48.3 & \\
\hline High & 266 & 47.1 & 127 & 52.5 & 139 & 43.0 & \\
\hline Not specified & 29 & 5.1 & 10 & 4.1 & 19 & 5.9 & \\
\hline
\end{tabular}

Other specialists such as endocrinologists, haematologists and andrologists were only sporadically. None of the participants stated that they had consulted a specialist for skin and sexually transmitted diseases. Only about every 4th woman and every 10th man had had the conversation about a possible infertility being initiated by their firstly contacted doctor. The patients' needs differed from this reality: Every third man and even every second women wished that the physician would initiate a conversation about the topic. Additionally, approximately every third man and every fifth woman were indecisive and at least did not reject the idea of a consultation initiated by the doctor. It must be emphasised that only every 9th man and every 4th woman was informed that treatments at a

Table 2 Type of first physician contacted by the patient, reported initiation of conversation by physician and patient attitude towards initiation of conversation by physician

\begin{tabular}{|c|c|c|c|c|c|c|c|}
\hline & \multicolumn{2}{|l|}{ Total } & \multicolumn{2}{|l|}{ Men } & \multicolumn{2}{|l|}{ Women } & \multirow[t]{2}{*}{$p$-value } \\
\hline & $n=565$ & $\%$ & $n=242$ & $\%$ & $n=323$ & $\%$ & \\
\hline \multicolumn{3}{|c|}{ First medical consultation with... } & & & & & $<0.001$ \\
\hline Gynaecologist & 313 & 55.4 & 14 & 5.8 & 299 & 92.6 & \\
\hline General Practitioner & 39 & 6.9 & 29 & 12.0 & 10 & 3.1 & \\
\hline Urologist & 109 & 19.3 & 107 & 44.2 & 2 & 0.6 & \\
\hline Other (Ref.) & 8 & 1.4 & 4 & 1.7 & 4 & 1.2 & \\
\hline No first consultation & 96 & 17.0 & 88 & 36.4 & 8 & 2.5 & \\
\hline \multicolumn{3}{|c|}{ Doctor initiated conversation... } & & & & & $<0.001$ \\
\hline Yes & 100 & 17.7 & 25 & 10.3 & 75 & 23.2 & \\
\hline No & 354 & 62.7 & 121 & 50.0 & 233 & 72.1 & \\
\hline No first consultation & 96 & 17.0 & 88 & 36.4 & 8 & 2.5 & \\
\hline Not specified & 15 & 2.7 & 8 & 3.3 & 7 & 2.2 & \\
\hline \multicolumn{3}{|c|}{ Doctor should initiate conversation... } & & & & & $<0.001$ \\
\hline Yes & 265 & 46.9 & 82 & 33.9 & 183 & 56.7 & \\
\hline No & 141 & 25.0 & 69 & 28.5 & 72 & 22.3 & \\
\hline I don't know & 159 & 28.1 & 91 & 37.6 & 68 & 21.2 & \\
\hline
\end{tabular}




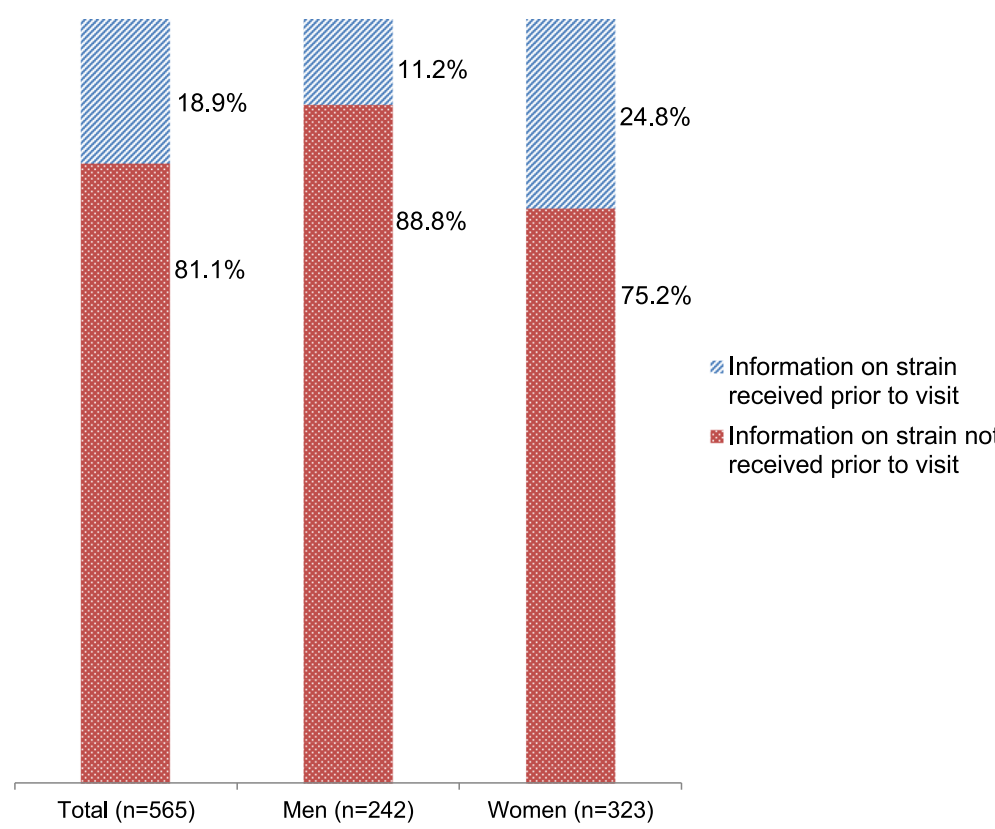

Fig. 1 Receiving information on possible emotional strain prior the visit in a fertility clinic, PinK study $(p<0.001)$

fertility clinic could be emotionally straining, despite binding guidelines for statutory health insurance-accredited physicians requiring that patients have to be briefed on medical, psychological and social aspects of fertility treatment before their referral to a fertility clinic [18].

When interpreting the results, the reader needs to be aware that only patients of selected fertility clinics were surveyed. These patients only represent the part of the group of individuals with an unfulfilled desire for a child that is using medical services and is potentially accepting health risks due to reproductive treatment. But it is known that $10-50 \%$ of all couples struggling with an unfulfilled desire for a child do not seek medical help $[10,11,26]$ and in some other cases sufficient medical support can be rendered without the need for a referral to a fertility clinic, for example through monitoring of the menstrual cycle or hormonal stimulation therapy. The PinK study does not give an insight into the medical care received by those infertile couples that do not start treatment at a fertility clinic. It also does not give any information about the selection mechanisms on the way to a fertility clinic or on the factors that decide whether a couple seeks treatment at a fertility clinic.

The following limitations apply to our results:

Selection bias could have occurred at a participation rate of $31 \%$. A test of the study population's representativeness of all couples at the beginning of infertility treatment was not possible due to the lack data on socio-economic variables for the latter population, e.g. in the German IVF register $[14,15]$. It is notable that only very few participants (3.5\%) have a "low education level". It is possible that patients with low income utilise services at fertility clinics less frequently due to the often required financial commitment or inadequate information about treatment options. Future research will have to determine whether access and utilisation of ART treatments are unequally distributed by income in the German health care system. Also, bias in the patient selection by staff members of the fertility clinics handing out the study documents cannot be ruled out. However, this bias should have been counteracted against by the use of standardised inclusion criteria and frequent preventative communication between the coordinating study centre and staff at the fertility clinics.

It is lastly possible that an information bias, especially due to socially desirable response behaviour, may have occurred, although socially desirable response behaviour should have been prevented through ensuring full anonymity in the survey. Information bias was also mitigated by the standardisation of the survey instrument and the preceding pilot study [25].

A health care gap for men can be identified since approximately one third of male participants did not have any medical conversation about the unfulfilled desire for a child outside the fertility clinic. This result is supported by a recently conducted survey of childless persons in Germany, showing that involuntarily childless men have undergone medical examination for infertility less than half as often as women across all age groups (for example $12 \%$ men vs. $46 \%$ women aged 40 to 50 years) [26]. Need for counselling for infertile men is indicated since it is proven that male causes of infertility are involved in about $50 \%$ of 
infertile couples in Europe and the US [27] and that men also experience grief and elevated levels of infertility-related anxiety before and during infertility treatment $[2,28]$. On the one hand, it is known that men show a lower general health care utilization than women $[29,30]$. On the other hand, there seems to be a lack of a dedicated medical contact person for fertility problems for men as opposed to for women. Medical check-ups at the gynaecologist might lead to a more frequent consideration of a women's fertility and wish for a child.. Men are lacking a comparable, low threshold contact in the health care system. As the GP is a physician that men might be comparatively regularly in contact with for a number of preventative as well as curative measures, he could be an important and feasible first contact person for men with regard to fertility questions. In Great Britain, the GP is officially recommended as the first medical contact person concerning such matters [31]. There, the majority of patients agrees with the GP's involvement, only $3 \%$ reject it [32].

Considering that formal support is especially important for infertile men as they are less likely than women to seek informal support in their social network and are more prone to withdrawal [2], the health care gap for infertile men in Germany urgently needs to be closed. Due to the low threshold, family-oriented approach of GPs and the trust placed in them by men and women alike, they might be able to discuss fertility problems and give medical information on the possibilities of possible treatments. They could also help to lower unrealistically high expectations regarding the prospect of reproductive medical treatments and offer advice regarding alternatives.

A part of the patient collective would like to be approached by their doctor regarding an unfulfilled desire for a child. But in a survey of 25 GPs in a German city for example, only few GPs reported having in fact initiated a conversation about fertility problems [33]. The new findings reported here should motivate doctors to address the topic of fertility and according problems.

It would definitely be of advantage and is also a legal obligation for statutory co-payment for ART treatment in Germany that doctors referring to a fertility clinic inform the patients about treatments, alternatives and possible strain $[31,34]$. An earlier study has already suggested that patients wish for more information on the possible psychological strain during the treatment [35]. This information need is further supported by results from a study on childless men and women in Germany that found that far more men and women have heard about treatment measures (e.g. IVF, insemination and sperm or egg donation) than of psychosocial counselling and psychotherapy for persons with an unfulfilled desire for a child. The degree of familiarity with the latter services amounted to only $45 \%$, respectively $46 \%$ among men and $53 \%$, respectively $57 \%$ among women [26].

\section{Conclusions}

Results from the PinK survey show for the first time that many different groups of physicians are involved in their patients' infertility problems in Germany and that health care services need to be improved, especially with regard to men.

Further nationwide representative surveys are necessary to fully analyse the medical care situation of all people with an unfulfilled desire for a child and to comprehensively conclude the possible courses of action.

Access to health care and consultation in case of an unfulfilled desire for a child should be obstacle-free and provided in a timely manner. This is equally important for men and for women as infertility treatment always affects the infertile couple and is not limited to one of the partners. Whereas women usually consult the gynaecologist in the case of an unfulfilled desire for a child, a health care gap still needs to be closed for men in Germany. The increased involvement of the GP could be helpful here as he is usually timely available and offers a low threshold, discreet access to an initial consultation and thereby to an introduction to the topic especially for men.

\section{Abbreviations \\ PinK: Paare in Kinderwunschtherapie [German: Couples in Infertility Treatment]; ART: Assisted Reproduction Technologies; ICSI: Intracytoplasmic Sperm Injection; IVF: In Vitro Fertilisation; OHSS: Ovarian Hyperstimulation Syndrome; ISCED: International Standard Classification of Education; GP: General Practitioner}

\section{Acknowledgements}

The cooperation with the directors of the fertility clinics and their staff made the PinK study possible in the first place. Special thanks goes to the Fertility Clinic Mainz (locations Mainz and Worms), Fertility Clinic Ludwigshafen, Fertility Clinic Middle Rhine (locations Koblenz and Neuwied), the University Fertility Clinic Mainz, the Practice Clinic Trier for Couples with an Unfulfilled Desire for a Child in Trier and the MVZ Fertility Clinic Wiesbaden GmbH.

\section{Funding}

The PinK study was financially supported by the intramural research funding of the Johannes Gutenberg University of Mainz. The funding body accepted the study as proposed and played no role in either the design of the study, the collection, analysis, and interpretation of data or writing the manuscript.

Availability of data and materials

Data will not be shared because planned analyses on the various issues are not yet fully launched by the interdisciplinary research group and not all results are published.

\section{Authors' contributions}

EM analysed the data and drafted and revised the paper. She is guarantor. UZ drafted and revised the paper. SL, JPW, NFS, BS, RS revised the paper. EM, $S L$, JPW, NFS, BS, RS, UZ initiated the study; EM, JPW, UZ designed data collection tools, monitored data collection, and revised the paper. All authors read and approved the final manuscript.

\section{Ethics approval and consent to participate}

The PinK study was presented to the Commissioner for Data Protection of Rhineland-Palatinate and Hesse and was approved by the ethics committees of the State Chambers of Medicine of both federal states in Germany. Participants received an information sheet briefing them on the purpose of the study as well as on the anonymity and the voluntariness of participation. Participants consented by using the return envelope to send in the questionnaire. 


\section{Consent for publication}

All authors read and approved the final manuscript. Consent to publish by participants was not applicable due to the manuscript containing no information by which participants can be personally identified.

\section{Competing interests}

RS is head of the fertility centre of the University Medical Center of the Johannes Gutenberg University Mainz. The other authors declare that they have no competing interests.

\section{Publisher's Note}

Springer Nature remains neutral with regard to jurisdictional claims in published maps and institutional affiliations.

\section{Author details \\ 'Institute of General Practice and Family Medicine, University of Bonn, Bonn, Germany. ${ }^{2}$ Institute of Occupational, Social and Environmental Medicine, University Medical Center of the University of Mainz, Mainz, Germany. ${ }^{3}$ Federal Institute for Population Research (BIB), Wiesbaden, Germany. ${ }^{4}$ Protestant University of Applied Sciences of Darmstadt, Darmstadt, Germany. ${ }^{5} \mathrm{Clinic}$ and Polyclinic for Obstetrics and Gynaecology, University Medical Center, University of Mainz, Mainz, Germany.}

Received: 17 July 2016 Accepted: 23 February 2018 Published online: 05 March 2018

\section{References}

1. Cousineau TM, Domar AD. Psychological impact of infertility. Best Pract Res Clin Obstet Gynaecol. 2007;21:293-308. https://doi.org/10.1016/j.bpobgyn. 2006.12.003.

2. Fisher JR, Hammarberg K. Psychological and social aspects of infertility in men: an overview of the evidence and implications for psychologically informed clinical care and future research. Asian J Androl. 2012;14:121-9. https://doi.org/10.1038/aja.2011.72.

3. Jacob MC, McQuillan J, Greil AL. Psychological distress by type of fertility barrier. Hum Reprod. 2007:22:885-94. https://doi.org/10.1093/humrep/del452.

4. Greil AL, McQuillan J, Lowry M, Shreffler KM. Infertility treatment and fertility-specific distress: a longitudinal analysis of a population-based sample of U.S. women. Soc Sci Med. 2011;73:87-94. https://doi.org/10.1016/ j.socscimed.2011.04.023.

5. Gana K, Jakubowska S. Relationship between infertility-related stress and emotional distress and marital satisfaction. J Health Psychol. 2014;21:104354. https://doi.org/10.1177/1359105314544990.

6. Menning BE. The emotional needs of infertile couples. Fertil Steril. 1980; 34:313-9.

7. Gameiro S, Boivin J, Dancet E, de Klerk C, Emery M, Lewis-Jones C, et al. ESHRE guideline: routine psychosocial care in infertility and medically assisted reproduction-a guide for fertility staff. Hum Reprod. 2015;30: 2476-85. https://doi.org/10.1093/humrep/dev177.

8. Greil AL, McQuillan J. Trying. Times Medical Anthropology Quarterly. 2010; 24:137-56. https://doi.org/10.1111/j.1548-1387.2010.01094.X.

9. Zegers-Hochschild F, Adamson GD, de Mouzon J, Ishihara O, Mansour $\mathrm{R}$, Nygren $\mathrm{K}$, et al. International Committee for Monitoring Assisted Reproductive Technology (ICMART) and the World Health Organization (WHO) revised glossary of ART terminology, 2009. Fertil Steril. 2009;92: 1520-4. https://doi.org/10.1016/j.fertnstert.2009.09.009.

10. Boivin J, Bunting L, Collins JA, Nygren KG. International estimates of infertility prevalence and treatment-seeking: potential need and demand for infertility medical care. Hum Reprod. 2007;22:1506-12. https://doi.org/10, 1093/humrep/dem046.

11. Helfferich C. Frauen Leben: Eine Studie zu Lebensläufen und Familienplanung. Köln: Bundeszentrale für gesundheitliche Aufklärung; 2001.

12. Ziller V, Hadji P, Thielscher C, Ziller M, Kostev K. Prevalence of female subfertility in German gynecological practices. Gynecol Endocrinol. 2013;29: 767-70. https://doi.org/10.3109/09513590.2013.798274

13. Calhaz-Jorge C. Assisted reproductive technology in Europe, 2012: results generated from European registers by ESHRE. Hum Reprod. 2016;31:1638-52.

14. Deutsches IVF-Register. DIR Jahrbuch 2015. Journal für Reproduktionsmedizin und Endokrinologie 2016;13(1 Spec No):6-44.
15. Deutsches IVF-Register. DIR Jahrbuch 2014. Journal für Reproduktionsmedizin und Endokrinologie 2015;12(1 Spec No):6-41.

16. Adamson GD, Tabangin M, Macaluso M, de Mouzon J. The number of babies born globally after treatment with the assisted reproductive technologies (ART). Fertil Steril. 2013;100 Suppl:S42. https://doi.org/10.1016/j. fertnstert.2013.07.1807.

17. Bundesärztekammer. (Muster-)Richtlinie zur Durchführung der assistierten Reproduktion. Novelle 2006. Deutsches Ärzteblatt. 2006;103:A1392-403.

18. Gemeinsamer Bundesausschuss. Richtlinien des Bundesausschusses der Ärzte und Krankenkassen über ärztliche Maßnahmen zur künstlichen Befruchtung. 2017. https://www.g-ba.de/informationen/richtlinien/1/. Accessed 19 Oct 2017

19. Borkenhagen A, Brahler E, Kentenich H. Attitudes of German infertile couples towards multiple births and elective embryo transfer. Hum Reprod. 2007:22:2883-7. https://doi.org/10.1093/humrep/dem296.

20. Schmidt L. Psychosocial burden of infertility and assisted reproduction. Lancet. 2006;367:379-80. https://doi.org/10.1016/S0140-6736(06)68117-8.

21. Rockliff HE, Lightman SL, Rhidian E, Buchanan H, Gordon U, Vedhara K. A systematic review of psychosocial factors associated with emotional adjustment in in vitro fertilization patients. Hum Reprod Update. 2014;20: 594-613. https://doi.org/10.1093/humupd/dmu010.

22. Wischmann T. Psychosoziale Aspekte bei Fertilitätsstörungen. Urologe. 2005:185-95

23. Boivin J, Lancastle D. Medical waiting periods: imminence, emotions and comping. Women's Health. 2011;6:59-69.

24. Stoebel-Richter Y, Geue K, Borkenhagen A, Braehler E, Weidner K. What do you know about reproductive medicine? - results of a German representative survey. PLoS One. 2012;7:e50113. https://doi.org/10.1371/ journal.pone.0050113.

25. Passet-Wittig J, Letzel S, Schneider NF, et al. The PinK study - methodology of the baseline survey of a prospective cohort study of couples undergoing fertility treatment. Wiesbaden: Federal Institute for Population Research; 2014. p. 36. (BiB Daten- und Methodenberichte; 1/2014)

26. Wippermann C. Kinderlose Frauen und Männer. Berlin: Bundesministerium für Familie, Senioren, Frauen und Jugend; 2014. p. 190.

27. Agarwal A, Mulgund A, Hamada A, Chyatte. A unique view on male infertility around the globe. Reprod Biol Endocrinol. 2015;13:37. https://doi. org/10.1186/s12958-015-0032-1

28. Petok WD. Infertility counseling (or the lack thereof) of the forgotten male partner. Fertil Steril. 2015;104:260-6. https://doi.org/10.1016/j. fertnstert.2015.04.040

29. Thode N, Bergmann E, Kamtsiuris P, Kurth BM. Predictors for ambulatory medical care utilization in Germany. Bundesgesundheitsblatt Gesundheitsforschung Gesundheitsschutz. 2005:48:296-306. https://doi.org/ 10.1007/s00103-004-1004-3.

30. Pinkhasov RM, Wong J, Kashanian J, Lee M, Samadi DB, Pinkhasov MM, Shabsigh R. Are men shortchanged on health? Perspective on health care utilization and health risk behavior in men and women in the United States. Int J Clin Pract. 2010;64:475-87. https:/doi.org/10.1111/j.1742-1241.2009.02290.x.

31. Wilkes $\mathrm{S}$, Chinn DJ, Murdoch A, Rubin G. Epidemiology and management of infertility: a population-based study in UK primary care. Fam Pract. 2009;26: 269-74. https://doi.org/10.1093/fampra/cmp029.

32. Wilkes S, Hall N, Crosland A, Murdoch A, Rubin G. Patient experience of infertility management in primary care: an in-depth interview study. Fam Pract. 2009;26:309-16. https://doi.org/10.1093/fampra/cmp039.

33. Ittner E, Himmel W, Kochen MM. Gehört das Problem "ungewollte Kinderlosigkeit" zum familienmedizinischen Auftrag des Hausarztes? Psychother Psychosom Med Psychol. 1997;47:263-70.

34. Himmel W, et al. Management of involuntary childlessness. Br J Gen Pract. 1997:47:111-8

35. Rauprich O, Berns E, Vollmann J. Information provision and decision-making in assisted reproduction treatment: results from a survey in Germany. Hum Reprod. 2011;26:2382-91. https://doi.org/10.1093/humrep/der207. 